\title{
Isolation and In Silico Analysis of Iron Regulated Transporter 2 Gene from Indian Barnyard Millet (Echinochloa frumentacea L.)
}

\author{
T.K. Manape ${ }^{1}$, S. Varanavasiappan ${ }^{1}$, M. Raveendran ${ }^{1}$, S. Robin ${ }^{2}$, \\ S. Rajeswari ${ }^{2}$ and D. Sudhakar ${ }^{1} *$ \\ ${ }^{1}$ Department of Plant Biotechnology, Centre for Plant Molecular Biology and Biotechnology, \\ Tamil Nadu Agricultural University, Coimbatore, Tamil Nadu, India \\ ${ }^{2}$ Centre for Plant Breeding and Genetics, Tamil Nadu Agricultural University, Coimbatore, \\ Tamil Nadu, India \\ *Corresponding author
}

\author{
A B S T R A C T
}

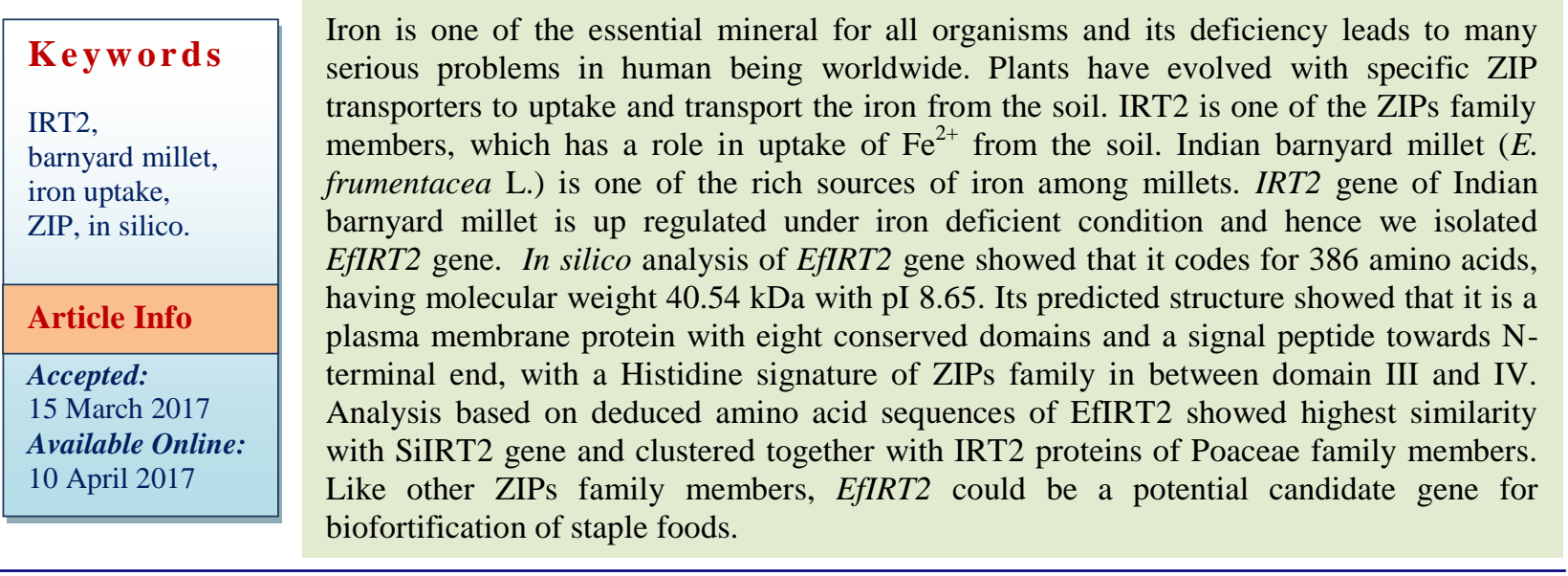

\section{Introduction}

Iron is an essential micronutrient and $\mathrm{Fe}$ deficiency is one of the most prevalent micronutrient deficiencies affecting around 2 billion people globally (Stoltzfus et al., 1998). About $30 \%$ of the global population is reported to be affected by anaemia due to $\mathrm{Fe}$ deficiency and it is also reported that 0.8 million deaths are caused annually due to $\mathrm{Fe}$ deficiency (WHO, 2002). Fe deficiency is ranked at sixth position among the risk factors of death and disability in developing countries with high mortality rates (WHO, 2002).
Fe deficiency is managed through food supplements and pills, which are not sustainable interventions in developing countries. Biofortification of staple food crops with enhanced iron in edible parts seems to be a viable strategy in bringing out sustainable solution to this problem. There are different approaches to enhance the iron content in crop plants. Application of $\mathrm{Fe}$ containing fertilizers, either by fertigation or foliar spray, can have significant effect on the accumulation of nutrients in edible plant 
products (Grunes and Allaway, 1985). Secondly, genetic manipulation of iron content in food grains/vegetables through various breeding methods holds promising role in enriching iron in staple food crops (Goudia and Hash, 2015). Enhancement of iron through conventional breeding methods has resulted in only 2-3 fold increase in iron content, which is insufficient to reach the required target levels of $14 \mu \mathrm{g} / \mathrm{g}$.

On the other hand, several attempts have been made through genetic engineering approaches to fortify staple food crops viz., rice, wheat and maize using candidate genes such as iron accumulation gene like OsIRTI (Lee and An, 2009), iron chelator gene $H v N A S$ (Masuda et al., 2008), seed-specific expression of storage protein, ferritin (Vasconcelos et al., 2003) and enhancing iron bioavailability using phytase (Afphytase) which degrades phytic acid (Lucca et al., 2001). These studies have led to development of rice lines with enhanced iron accumulation in endosperm $(15 \mu \mathrm{g} / \mathrm{g} \mathrm{Fe}$ in polished rice) by over-expressing genes viz., nicotianamine synthesis 2 (OsNAS2) and soybean ferritin (Trijatmiko et al., 2016). Based on results of several experiments, it is postulated that synergistic improvement of iron mobilization in soil, uptake of $\mathrm{Fe}$ by roots, transport of $\mathrm{Fe}$ from roots to shoots and finally accumulation in grains will help in developing crop varieties with enhanced iron in grains or edible parts.

Although iron is the fourth most metal element found in the earth's crust, its low solubility makes it unavailable to plant roots. Plants have evolved specialized system to take up iron from soil.

Fe transporter gene namely Iron Regulated Metal Transporter 1 (IRTI) has been established as the major iron uptake system from the soil, and candidate for iron biofortification (Tan et al., 2014, Boonyaves et al., 2016). IRTs are the members of the
Zinc-Regulated Transporter/Iron-Regulated Transporters (ZRT/IRTs)-Related Protein (ZIP) transporter family. Among the IRT gene family members, IRT2 is expressed in the outer layer of the root epidermal cells of Arabidopsis thaliana and upregulated under iron deficient condition, but to a lesser extent (Vert et al., 2001). Role of IRT2 in uptake of $\mathrm{Fe}$ and avoiding transport of manganese and cadmium has been reported (Vert et al., 2002; Shanmugam et al., 2011). This has made IRT 2 as one of the potential targets for genetic manipulation of iron accumulation in rice. In this context, identification of superior rice/cereal genotype exhibiting enhanced iron uptake/accumulation in grains and isolation of IRT from those genetic sources for genetic engineering applications are crucial in achieving the desired target.

Barnyard millet (Echinochloa sp.) is one of the oldest domesticated millets belonging to Poaceae family in the semi-arid tropics of Asia and Africa (Doggett, 1986). Indian barnyard millet ( $E$. Frumentacea L.) is reported to possess fairly high level of digestible protein $(12 \%)$, low carbohydrate content $(58.56 \%)$, and rich amount of iron ranging from 19.56 to $42.13 \mu \mathrm{g} / \mathrm{g}$ in grains (Chandel et al., 2014; Patel et al., 2015).

Among cereals the presence of IRTI and IRT2 genes have been predicted in Oryza sativa, Oryza brachyantha, Brachypodiun distachyon, Setaria italica, Sorghum bicolor, Zea mays, Hordeum vulgare, etc., but no efforts have been made to isolate and characterize $I R T$ genes in an iron rich small millet $E$. frumentacea. In this study, we isolated a full-length gene encoding EfIRT2 and predicted its physical and chemical properties using bioinformatics tools. This is the first report on isolation and characterization of an iron regulated transporter 2 gene from Indian barnyard millet. 


\section{Materials and Methods}

\section{Amplification of partial fragment of EfIRT2 gene}

Genetically pure seeds of Indian barnyard millet (E. frumentacea L. cv. CO 1) were sown on the soil and genomic DNA was extracted from $0.5 \mathrm{~g}$ of leaf samples collected from 7 day-old seedlings by CTAB method (Doyle and Doyle, 1987) with slight modifications for amplification of full-length EfIRT2 gene from genomic DNA.

IRT2 genomic DNA sequences of 7 species of Poaceae family; viz. $B$. distachyon, $H$. vulgare, O. sativa, O. brachyantha, S. italica, $S$. bicolor and $Z$. mays, were retrieved from Phytozyme $v 9.1$ and aligned using ClustalX $v 2.0$ online tool. The degenerate primer set (dIRT2-F1 and dIRT2-R2, Table 1) was designed in highly conserved region. Partial fragment of IRT2 gene sequence was PCR amplified by using $50 \mathrm{ng}$ genomic DNA as template using PCR conditions of initial denaturation for $5 \mathrm{~min}$ at $94{ }^{\circ} \mathrm{C}$ followed by 35 cycles of $1 \mathrm{~min}$ at $94{ }^{\circ} \mathrm{C}, 1 \mathrm{~min}$ at $58{ }^{\circ} \mathrm{C}$ $1.30 \mathrm{~min}$ at $72{ }^{\circ} \mathrm{C}$ and final extension for 10 min at $72{ }^{\circ} \mathrm{C}$. The amplified fragment was purified using PCR product purification kit (BioBasic Inc. Canada) and sequenced (Scigenom Pvt. Ltd., Cochin).

\section{Amplification and cloning of full-length genomic DNA encoding EfIRT2}

The 5' and 3' ends of EfIRT2 were amplified by thermal asymmetric interlaced PCR (TAIL-PCR) as described by Liu et al., (1995). Following gene specific primers were used to amplify 5' end (5P, 5S, 5T; Table 1) and 3' end (3P, 3S, 3T; Table 1) along with 6 degenerate primers (AD1, AD2, AD3, AD4, AD5 and AD6; Table 1). The tertiary products of TAIL-PCR were purified and sequenced. The overlapping sequences of 5' and 3' ends of IRT2 gene were aligned with partially amplified fragment to obtain fulllength nucleotide sequence of IRT2 gene. The ORF and intron region of EfIRT2 gene were predicted by FGENESH online tool (http://www.softberry.com/berry.phtml?topic= fgenesh\&group=programs\&subgroup=gfind) using $S$. italica IRT2 gene as a reference gene. The full-length IRT2 gene was amplified from genomic DNA with ORF specific primer set (ORF_F and ORF_R, Table 1) using proof reading XT-5 polymerase (Genei, Bangalore). PCR conditions used were initial denaturation for 5 min at $94^{\circ} \mathrm{C}$ followed by 35 cycles of $45 \mathrm{sec}$ at $94{ }^{\circ} \mathrm{C}, 45 \mathrm{sec}$ at $62{ }^{\circ} \mathrm{C}, 90 \mathrm{sec}$ at $72{ }^{\circ} \mathrm{C}$ and final extension for $10 \mathrm{~min}$ at $72^{\circ} \mathrm{C}$. The PCR amplified product was resolved on $0.8 \%$ agarose gel. Amplified IRT2 gene products were purified and cloned into pJET1.2 vector (ThermoScientific Inc. USA) and five independent positive clones were sequenced in both the directions.

\section{In silico analysis}

The ORF and intron region of EfIRT2 gene were predicted by FGENESH online tool. The nucleotide sequences of EfIRT2 gene from genomic DNA and predicted ORF (cDNA) were compared using ClustalW online tool to confirm the intron region predicted by FGENESH tool. Deduced amino acid sequence form predicted EfIRT2 ORF was used as a query to identify homologous genes in different plant species using BLASTp search tool against protein sequences in the NCBI database (http://blast.ncbi.nlm.nih.gov/Blast.cgi).

Multiple sequence alignment of other known IRT sequences from related crop species viz. S. italica IRT2 (XP_004986332.1), O. sativa IRT2 (XP_015629246.1), O. brachyantha IRT2 (XP_006651668.1), S. bicolor hypothetical protein (XP_002464109.1), Z. 
mays hypothetical protein (XP_008665793.1), S. italica IRT1 (XP_004982221.1), O. sativa IRT1 (XP_015632375.1), B. distachyon IRT1 (XP_014752016.1), and $H$. vulgare IRT (ACD71460.1), was carried out using CLUSTALW tool in BioEdit software in order to find conserved domains. This amino acids alignment was used for phylogenetic analysis by MEGA6 software using the maximum likelihood method with 1,000 bootstrap replications by Poisson model.

Various other properties viz., secondary structure (PSIPHRED; http://bioinf.cs.ucl. ac.uk/psipred/); pI/Mw (Compute $\mathrm{pI} / \mathrm{Mw}$; http://web.expasy.org/compute_pi/); subcellular localization (ProtCompv9.0; http://www.softberry.com/berry.phtml?topic= protcomppl) and trans-membrane protein prediction (DAS-TMfilter server; http://mendel.imp.ac.at/sat/DAS/DAS.html) were also analyzed.

\section{Results and Discussion}

\section{Isolation of EfIRT2 gene}

Partial fragment of approximately 950 bp was PCR amplified from barnyard millet genomic DNA using a pair of primers designed in conserved domain (Figure 1a) and the amplified DNA was sequenced. TAIL-PCR resulted in the amplification of $250 \mathrm{bp}$ fragment at the 5'end and $150 \mathrm{bp}$ fragment at the 3 'end. These fragments were purified and sequenced. Using these 5'and 3'end sequences, full-length sequence of EfIRT2 was deduced and new primers were designed to amplify the full-length coding sequence of EfIRT2 from genomic DNA (Figure 1b).

Amplified full-length coding sequence was confirmed by sequencing. Genomic DNA sequences of EfIRT2 were deposited in NCBIGenBank database (Accession no. KX832298).

\section{In silico analysis of EfIRT2 gene}

ORF prediction of deduced nucleotide sequence by FGENESH tool and comparison of genomic DNA and predicted cDNA nucleotide sequences of EfIRT2 gene revealed that genomic DNA sequence of EfIRT2 gene had 1254 bp ORF, comprising two exons with an intron of size $93 \mathrm{bp}(+706$ to $+798 \mathrm{bp})$ (Fig. 2). BLASTn results showed that EfIRT2 gene sequence shared significant homology with IRT2 genes of other related crop species viz. 95\% with S. italica (XM_004986275.2), $91 \%$ with $O$. sativa, $90 \%$ with $O$. brachyantha and $90 \%$ with $Z$. mays. It also shared significant homology with IRTI gene of other grass family members viz. $90 \%$ with O. brachyantha, $89 \%$ with O. sativa, $89 \%$ with $S$. italica, $88 \%$ with $B$. distachyon and $86 \%$ with $Z$. mays (results not shown).

Conserved domain analysis by multiple sequence alignment of amino acids of EfIRT2 and other IRTs of related species revealed that it had 3 conserved domains, among them $\mathrm{C}$ terminal domain is highly conserved but $\mathrm{N}$ terminal domain exhibited greater degree of variation across different members (Figure 2). The phylogenetic tree was constructed based on the amino acid alignments of 10 IRT proteins. Phylogenetic analysis of EfIRT2 with other IRT2 family members of related species showed that EfIRT2 formed a close/tight lineage with predicted SiIRT2 whereas separate/distant lineage from IRT1 of other grass family species (Figure 3).

Prediction of putative secondary structure using PSIPHRED tool revealed that EfIRT2 protein contains 15 coils, 13 alpha helices and 6 beta-strands (Figure 4). It was predicted that it encoded a protein of 386 amino acids with a molecular mass of $40.54 \mathrm{kDa}$ and $\mathrm{pI}$ of 8.65. Sub-cellular localization by ProtComp $v 9.0$ online tool predicted that EfIRT2 protein was a typical plasma membrane transmembrane 
protein with a certainty score of 0.86 to/far 0.9 . The transmembrane prediction tool of EfIRT2 protein revealed that EfIRT2 protein has 8 potential transmembrane $\alpha$ helices (amino acids: 69-88, 104-117, 146-163, 236251, 265-269, 296-314, 324-350, 364-378). A highly conserved region containing the ZIP signature sequence of histidine motif (amino acid sequence HCHGHGHM, from 195-202, shown by $*$ in figure 2) was located in between III and IV transmembrane domain. A potential signal peptide (amino acid 8-24) was also predicted in the $\mathrm{N}$-terminal domain.

Iron is directly related to plant growth and development as it has a crucial role in biosynthesis and maintenance of chlorophyll structure and function (Terry and Abadia, 1986). Iron uptake and transport in plants influence iron accumulation in plant organs such as leaves, grains, and fruits, which are important food sources for humans and animals. ZIPs are the major $\mathrm{Fe}^{2+}$ transporter, both in graminaceous as well as in nongraminaceous plants. Under iron deficient conditions, significant induction of IRT2 was observed in root epidermal cells of Arabidopsis (Vert et al., 2001), green gram (Muneer et al., 2014) and tomato (Eckhardt et al., 2001). It has generally been reported that Fe transport genes are highly up-regulated during mineral starvation (Kerkeb et al., 2008; Shanmugam et al., 2011; Vert et al., 2002).

Since Indian barnyard millet belongs to Poaceae, EfIRT2 amino acid sequences showed maximum homology and formed a cluster in dendrogram with IRT2 of others members of Poaceae crops. EfIRT2 amino acid sequences showed maximum similarity (95\%) and tight lineage with S. italica IRT2, as both $S$. italica and E. Frumentacea are belonging to millet group and may have more genome similarity and hence IRT2 might be having similar function. Our results predicted that EfIRT2 is having 386 amino acids with a molecular mass of $40.54 \mathrm{kDa}$ and $\mathrm{pI}$ of 8.65. Similarly, Vatansever et al., (2015) have analyzed IRT2 from 8 different plant species and reported IRT2 having amino acid sequences ranging from 324 to 408 residues with molecular weights ranging from 33.86 to $41.38 \mathrm{kDa}$ and $\mathrm{pI}$ ranging from 6.11 to 6.85 .

In general, most of the eukaryotic transporters are located at membrane of chloroplast, vacuole, mitochondria, plasma membrane. ZIP family members have eight predicted transmembrane domains (Guerinot, 2000). Eide et al., (1996) reported that AtIRT1 is a transmembrane protein, with 8 transmembrane domains, a histidine motif in between transmembrane domain III and IV and a potential signal peptide (sensing domain). A highly conserved region containing histidine motif is the ZIP signature that proposed to be involved in the formation of a cytoplasmic metal binding site (Eide et al., 1996). Signal peptides are the N-terminal amino acid sequences that direct proteins to organelles like chloroplast, mitochondria and are required for their transport across membranes from their site of synthesis in the cytoplasm for post-translational modifications of proteins (Patron and Walker, 2007). Sensing domain of AtIRT1 might mediate posttranslational regulation (Eide et al., 1996; Guerinot, 2000). Our results also predicted that EfIRT2 is a typical plasma membrane transmembrane protein with 8 potential transmembrane $\alpha$ helices, histidine motif in between transmembrane domain III and IV and a potential signal peptide. Therefore, it is a member of ZIP family and a potential signal peptide may have a role in transport of EfIRT2 to the specified organelle for posttranslational modifications. In general, the protein has peculiar secondary structure, but their conserved domains in secondary structure helps in folding the proteins and determines the function (Fig. 5). 
Table.1 List of primers used in this study

\begin{tabular}{|l|l|l|}
\hline S. No & Primer name & Sequences $\left({ }^{\prime}\right.$ '..... $\left.{ }^{\prime}\right)$ \\
\hline 1 & dIRT2-F1 & CGCCTGAAGCTVATCG \\
\hline 2 & dIRT2-R2 & ACSAGCGCCATGTAGTG \\
\hline 3 & 5 P & TGTGGAAGGTGAGCATGAG \\
\hline 4 & $5 S$ & GTGAGGTCGTTGAAGGAG \\
\hline 5 & $5 \mathrm{~T}$ & GACGACGACGAAGAGGTTGC \\
\hline 6 & $3 \mathrm{P}$ & AGATGGGCATCGTGGTGCACT \\
\hline 7 & $3 \mathrm{~S}$ & GATGAAGTCGGTGCTGGTCT \\
\hline 8 & $3 \mathrm{~T}$ & ATCGTCGTCGGGCTGCTGAA \\
\hline 9 & AD1 & NGTCGASWGANAWGAA \\
\hline 10 & AD2 & TGWGNAGSANCASAGA \\
\hline 11 & AD3 & AGWGNAGWANCAWAGG \\
\hline 12 & AD4 & STTGNTASTNCTNTGC \\
\hline 13 & AD5 & NTCGASTWTSGWGTT \\
\hline 14 & AD6 & WCAGNTGWTNGTNCTG \\
\hline 15 & sqF & AGATGGGVATCGTGGTGCA \\
\hline 16 & sqR & CACTTGGCCATGACGGACAT \\
\hline 17 & ORF_F & ATGTCTTCACAAACAGTGCCAAG \\
\hline 18 & ORF_R & TCACGCCCACTTTGCCATG \\
\hline 19 & Act1F & TGTGATGTTGATATCAGGAAGGA \\
\hline 20 & Act1R & GGGACCGGTTTCGTCATACT \\
\hline & &
\end{tabular}

Fig.1 Amplification of EfIRT2 gene

(a)Genomic DNA of E. Frumentacea was used as a template for amplification of partial sequence of EfIRT2 ( $950 \mathrm{bp}$ ); (b)Amplification of full length sequence of EfIRT2 gene from

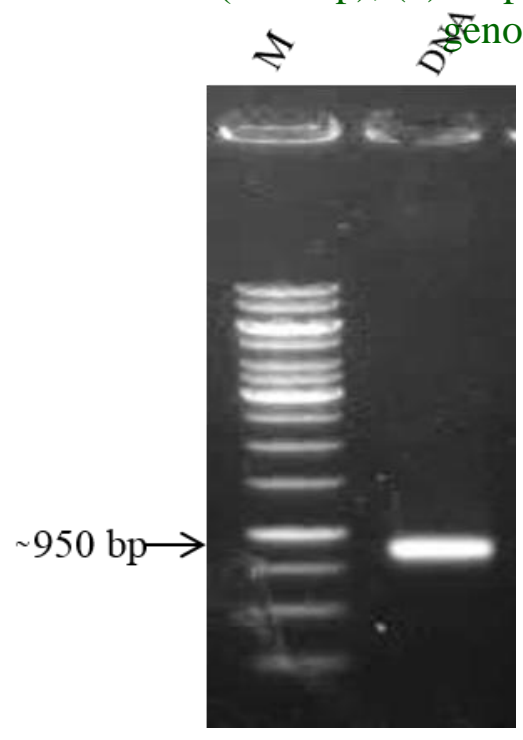

Figure 1a. Partial EfIRT2 c DNA (1254 bp)

M- $1 \mathrm{~kb}$ ladder.

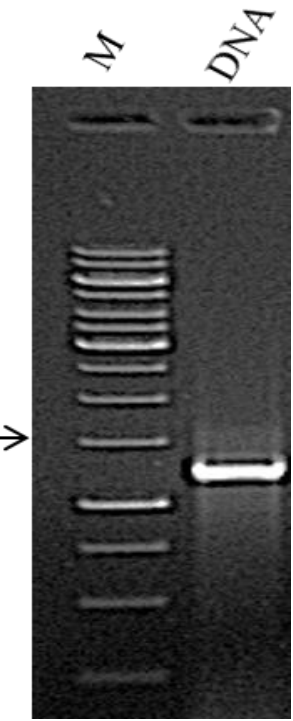

Figure 1b. Full length EfIRT2 
Fig.2 EfIRT2 gene nucleotide sequence comparison

\begin{tabular}{|c|c|c|}
\hline $\begin{array}{l}\text { gDNA } \\
\text { CDNA }\end{array}$ & $\begin{array}{l}\text { 5' UTR (-1 t -60 bp) } \\
\text { CAACGTGTACACACACACACACACACACTACACTAACGGTMTTAGCTCGAAGTACGTGAA }\end{array}$ & $\begin{array}{l}60 \\
0\end{array}$ \\
\hline $\begin{array}{l}\text { gDNA } \\
\text { CDNA }\end{array}$ & $\begin{array}{l}\text { Start } \\
\text { ATGICTTCACAAACAGTGCCAAGAGTGCTCGTTCTCACTCTCCTCGTGCTGCTCATACAC } \\
\text { ATGICTTCACAAACAGTGCCAAGAGTGCTCGTICTCACTCTCCTCGTGCTGCTCATACAC }\end{array}$ & $\begin{array}{l}120 \\
60\end{array}$ \\
\hline $\begin{array}{l}\text { gDNA } \\
\text { CDNA }\end{array}$ & $\begin{array}{l}\text { TCCTCGCTGCCCATCACCACCTTCGCACAACCCGCACCCGAACAATCGCCACCGGAAACG } \\
\text { TCCTCGCTGCCCATCACCACCTTCGCACAACCCGCACCCGAACAATCGCCACCGGAAACG }\end{array}$ & $\begin{array}{l}180 \\
120\end{array}$ \\
\hline $\begin{array}{l}\text { gDNA } \\
\text { CDNA }\end{array}$ & $\begin{array}{l}\text { GCGGCGACGACGACGACCCACGGCGTGTGCGGCGGCCCGACGGCGGGGCACAAGTGCCAC } \\
\text { GCGGCGACGACGACGACCCACGGCGTGIGCGGCGGCCCGACGGCGGGGCACAAGTGCCAC }\end{array}$ & $\begin{array}{l}240 \\
180\end{array}$ \\
\hline $\begin{array}{l}\text { gDNA } \\
\text { CDNA }\end{array}$ & $\begin{array}{l}\text { AGCGTGCCCAGGGCGCTGCGCCTGAAGCTGATCGCCATCCCGGCGATCCTCCTCGCCAGC } \\
\text { AGCGTGCCCAGGGCGCTGCGCCTGAAGCTGATCGCCATCCCGGCGATCCTCCTCGCCAGC }\end{array}$ & $\begin{array}{l}300 \\
240\end{array}$ \\
\hline $\begin{array}{l}\text { gDNA } \\
\text { CDNA }\end{array}$ & $\begin{array}{l}\text { ATGGCCGGCGTGTGCCTGCCCCTCCTCTCCCGCTCCGTGCCGGCGCTCCGCCCCGACGGC } \\
\text { ATGGCCGGCGTGTGCCTGCCCCTCCTCTCCCGCTCCGTGCCGGCGCTCCGCCCCGACGGC }\end{array}$ & $\begin{array}{l}360 \\
300\end{array}$ \\
\hline $\begin{array}{l}\text { GDNA } \\
\text { CDNA }\end{array}$ & $\begin{array}{l}\text { AACCTCTICGTCGTCGTCAAGGCCTTCGCGTCGGGGGTCATCCTCGGCACGGGGTACATG } \\
\text { AACCTCTTCGTCGTCGTCAAGGCCTTCGCGTCGGGGGTCATCCTCGGCACGGGGTACATG }\end{array}$ & $\begin{array}{l}420 \\
360\end{array}$ \\
\hline $\begin{array}{l}\text { gDNA } \\
\text { CDNA }\end{array}$ & $\begin{array}{l}\text { CACGTCCTCCCGGACTCCTICAACGACCTCACCTCGCCGTGCCTGCCGCGGAGGCCCTGG } \\
\text { CACGTCCTCCCGGACTCCTTCAACGACCTCACCTCGCCGTGCCTGCCGCGGAGGCCCTGG }\end{array}$ & $\begin{array}{l}480 \\
420\end{array}$ \\
\hline $\begin{array}{l}\text { gDNA } \\
\text { CDNA }\end{array}$ & $\begin{array}{l}\text { GCGGAGTTCCCGTTCACGGCGTTCGTCGCCATGCTCGCCGCCGTGTCCACGCTCATGCTG } \\
\text { GCGGAGTICCLGTICACGGCGTTCGICGCCATGCTCGCCGCCGIGTCCACGCTCATGCTG }\end{array}$ & $\begin{array}{l}540 \\
480\end{array}$ \\
\hline $\begin{array}{l}\text { gDNA } \\
\text { CDNA }\end{array}$ & $\begin{array}{l}\text { GACTCGCTCATGCTCACCTTCCACAGCCGGAGCAGGGGCAAGGCCAGCGCCGTCGTCGCG } \\
\text { GACTCGCTCATGCTCACCTTCCACAGCCGGAGCAGGGGCAAGGCCAGCGCCGTCGTCGCG }\end{array}$ & $\begin{array}{l}600 \\
540\end{array}$ \\
\hline $\begin{array}{l}\text { gDNA } \\
\text { CDNA }\end{array}$ & $\begin{array}{l}\text { CACCACGGCCATGGCGACAGCCCTCCTCCGCATAAGCCGGCTCACTGCCACGGGCACGGG } \\
\text { CACCACGGCCATGGCGACAGCCCTCCTCCGCATAAGCCGGCTCACTGCCACGGGCACGGG }\end{array}$ & $\begin{array}{l}660 \\
600\end{array}$ \\
\hline $\begin{array}{l}\text { gDNA } \\
\text { CDNA }\end{array}$ & $\begin{array}{l}\text { CATATGCTAGAGCTAGACATGACTCCAGCGACGCCGGAGGGCGCCGTGGACGACGACGTC } \\
\text { CATATGCTAGAGCTAGACATGACTCCAGCGACGCCGGAGGGCGCCGTGGACGACGACGTC } \\
\text { Intron (+706 to +798 bp) }\end{array}$ & $\begin{array}{l}720 \\
660\end{array}$ \\
\hline $\begin{array}{l}\text { gDNA } \\
\text { CDNA }\end{array}$ & $\begin{array}{l}\text { GAGGCCGGCAAAGCGCGGCTGCTCAGGAACCGTGTCATCGTTCAGGTAATCGATCGATCA } \\
\text { GAGGCCGGCAAAGCGCGGCTGCTCAGGAACCGTGTCATCGTTCAG----- }\end{array}$ & $\begin{array}{l}780 \\
705\end{array}$ \\
\hline $\begin{array}{l}\text { gDNA } \\
\text { CDNA }\end{array}$ & СGТТGСАТGСАСААС & $\begin{array}{l}840 \\
705\end{array}$ \\
\hline $\begin{array}{l}\text { gDNA } \\
\text { CDNA }\end{array}$ & 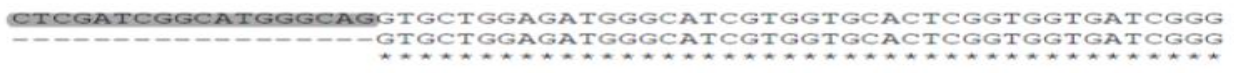 & $\begin{array}{l}900 \\
747\end{array}$ \\
\hline $\begin{array}{l}\text { gDNA } \\
\text { CDNA }\end{array}$ & $\begin{array}{l}\text { CTGGGCATGGGCGCGTCGCAGAACGTGTGCACGATCCGGCCGCTGGTGGCGGCACTCTGC } \\
\text { CTGGGCATGGGCGCGICGCAGAACGIGIGCACGATCCGGCCGCTGGTGGCGGCACTCTGC }\end{array}$ & $\begin{array}{l}960 \\
807\end{array}$ \\
\hline $\begin{array}{l}\text { gDNA } \\
\text { CDNA }\end{array}$ & 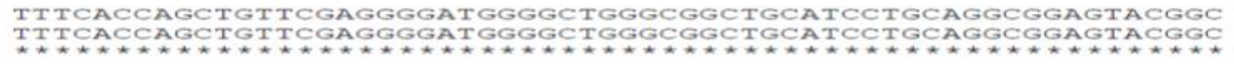 & $\begin{array}{l}1020 \\
867\end{array}$ \\
\hline $\begin{array}{l}\text { gDNA } \\
\text { CDNA }\end{array}$ & $\begin{array}{l}\text { GCCCGGATGAAGTCGGTGCTGGTCTTTTTTTTCTCCACGACGACGCCGTTCGGGATCGCG } \\
\text { GCCCGGATGAAGTCGGTGCIGGTCTTITITTTCTCCACGACGACGCCGTTCGGGATCGCG }\end{array}$ & $\begin{array}{l}1080 \\
927\end{array}$ \\
\hline $\begin{array}{l}\text { gDNA } \\
\text { CDNA }\end{array}$ & $\begin{array}{l}\text { CTGGGGCTCGCGCTCACCAGGGTGTACAGCGACAGCAGCCCGGCGGCGCTCATCGTCGTC } \\
\text { CTGGGGCTCGCGCTCACCAGGGTGTACAGCGACAGCAGCCCGGCGGCGCTCATCGTCGTC }\end{array}$ & $\begin{array}{l}1140 \\
987\end{array}$ \\
\hline $\begin{array}{l}\text { gDNA } \\
\text { CDNA }\end{array}$ & $\begin{array}{l}\text { GGGCTGCTGAACGCGGCGTCGGCGGGGCTGCTGCACTACATGGCGCTGGTGGACCTCCTG } \\
\text { GGGCTGCTGAACGCGGCGTCGGCGGGGCTGCTGCACTACATGGCGCTGGTGGACCTCCTG }\end{array}$ & $\begin{array}{l}1200 \\
1047\end{array}$ \\
\hline $\begin{array}{l}\text { gDNA } \\
\text { CDNA }\end{array}$ & $\begin{array}{l}\text { GCGGCGGACTTCATGGGGCCCAAGCTGCAGGGGAGCGTCAGGCTCCAGCTCGTCTCGTTC } \\
\text { GCGGCGGACTTCATGGGGCCCAAGCTGCAGGGGAGCGTCAGGCTCCAGCTCGTCTCGTTC }\end{array}$ & $\begin{array}{l}1260 \\
1107\end{array}$ \\
\hline $\begin{array}{l}\text { gDNA } \\
\text { CDNA }\end{array}$ & $\begin{array}{l}\text { CTCGCGGTCCTCCTCGGCGCCGGCGGCATGTCCGTCATGGCCAAGTGGGCG } \\
\text { CTCGCGMTGTATC } \\
\text { 3' UTR (+1255 to } \mathbf{+ 1 3 8 8} \mathbf{b p )}\end{array}$ & $\begin{array}{l}1320 \\
1161\end{array}$ \\
\hline $\begin{array}{l}\text { gDNA } \\
\text { CDNA }\end{array}$ & CCGAGAAGATCGAGCAGGCTGTCACGACAATTACGTIAGGTACAGGTGTTGTGTATATGT & $\begin{array}{l}1380 \\
1161\end{array}$ \\
\hline $\begin{array}{l}\text { gDNA } \\
\text { CDNA }\end{array}$ & GCTGTIAT & \\
\hline
\end{tabular}


Fig.3 Multiple sequence alignment of EfIRT2 protein

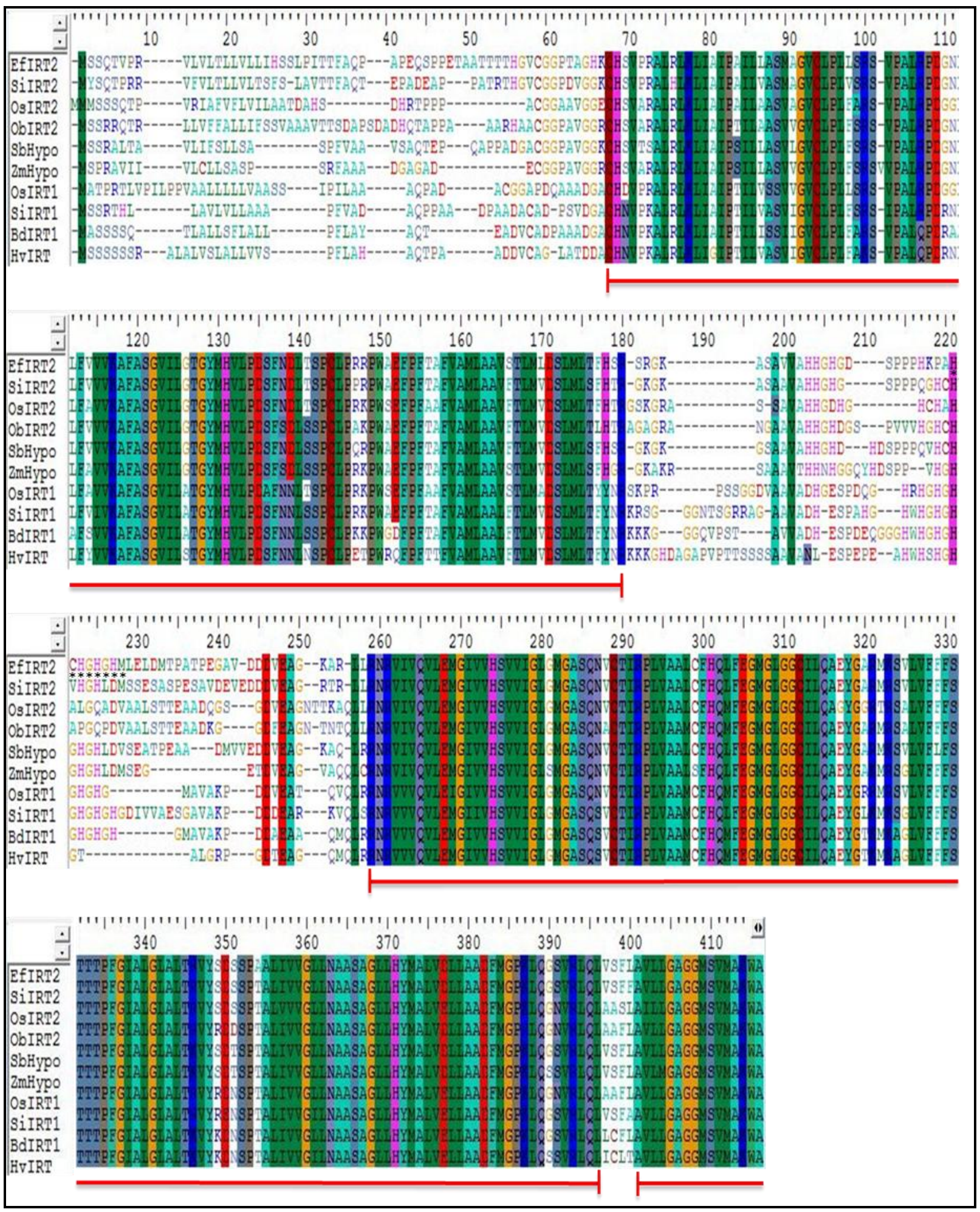


Fig.4 Phylogenetic analysis of EfIRT2 protein

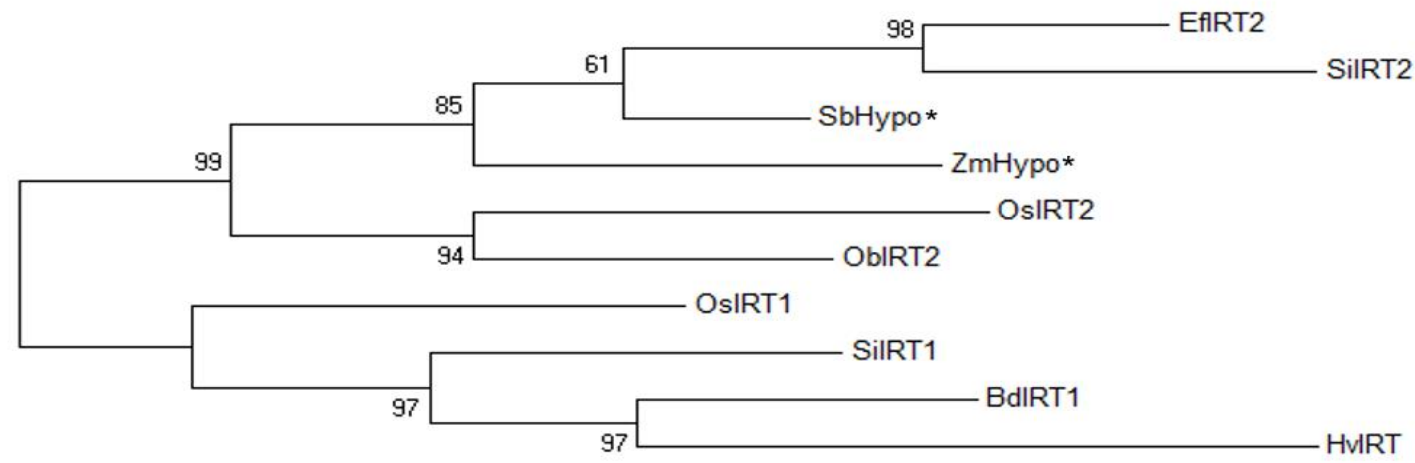

$\longmapsto 0.05$

Fig.5 Secondary structure prediction of EfIRT2 protein

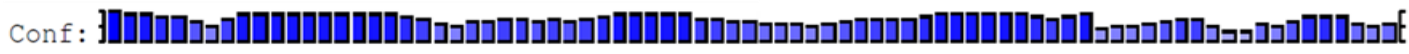

Pred: $\longrightarrow$

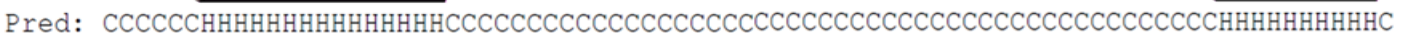

AA: MSSQTVPRVLVLTLLVLLIHSSLPITTFAQPAPEQSPPETAATTTTHGVC!GGTAGHKCHSVPRALRLKLIAIPAILLAS

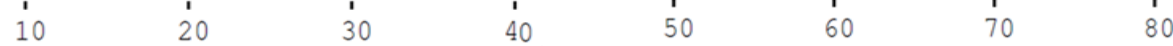



Pred:

Pred: CCCCCCCCCCCCCCCCCCCCCEEEEEEEHHCCEEEEECCCCCCCCHHCCCCCCCCCCCCCCCCCCHHHHHHHHHHHHHH

AA: MAGVCLPLLSRSVPALRPDGNLFVVVKAFASGVILGTGYMHVLPDSFNDLTSPCLPRRPWAEFPFTAFVAMLAAVSTLML

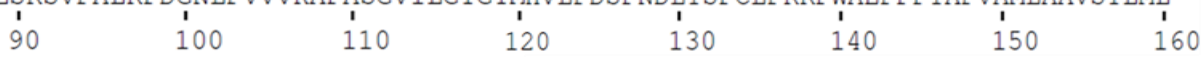

Conf:

Pred: $\longrightarrow-2$

Pred: CCCCCHHCCCCCCCCCCCCCCCCCCHHHHHHHHHHHHHHHHHHHHHHHHHCCCCCCCCCCCCCCCCCCCCCCCCCCCCCC

AA: HVLPDSFNDLTSPCLPRRP WAEFPFTAFVAMLAAVSTLMLDSLMLTFHSRSRGKASAVVAHHGHGDSPPPHKPAHCHGHG

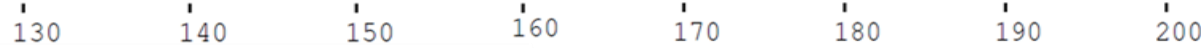

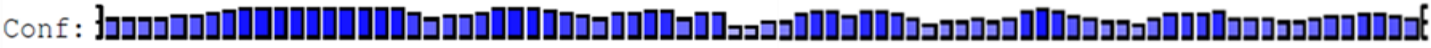

Pred: $\longrightarrow-\longrightarrow$

Pred: CCCCCCCCCCCCCCCCCCCHHHHHHHHHHHHHHHHEEECEEEEEEEEEEECCCCCCCCCCCCHHHHHHHHHHCCCCCCCC

AA: HMLELDMTPATPEGAVDDVEAGKARLLRNRVIVQVLEMGIVVHSVVIGLGMGASQNVCTIRPLVAALCFHQLFEGMGLG

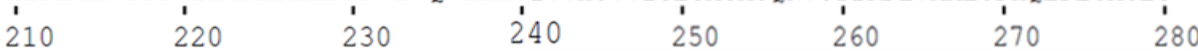

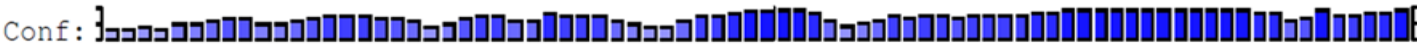

Pred: $\square \longrightarrow$

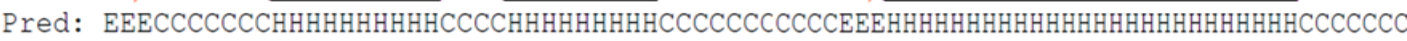

AA: GCILQAEYGARMKSVLVFFFSTTTPFGIALGLALTRVYS

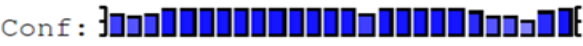

$\begin{array}{lllllll}1 & 1 & 1 & 1 & 1 & 1 & 1 \\ 290 & 300 & 310 & 320 & 330 & 340 & 350\end{array}$

Pred:

Pred: CHнHнHнннннннннннннннннCCC

AA: SVRLQLVSFLAVLLGAGGMȘVMAKWA

$370 \quad 380$

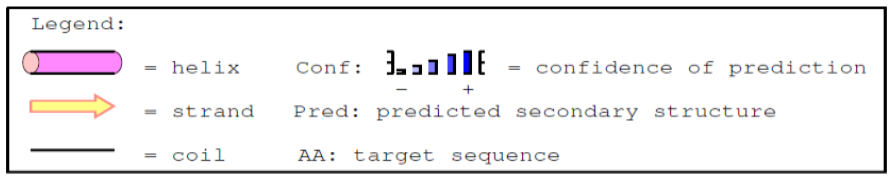

1584 
The amino acid sequence alignment results showed that there were 3 conserved domains in secondary structure of EfIRT2 which are highly conserved among other IRT2 of other species of Poaceae. It is hypothesized that EfIRT2 has function of Fe uptake similar to other ZIP family members.

In conclusion, this study shows that EfIRT2 gene possesses high similarity and tight lineage with other ZIPs members of Poaceae family, the encoded protein has presence of eight conserved transmembrane domains along with histidine signature of ZIPs family and its plasma membrane location. All these above characteristics of the gene are sufficient to consider the EfIRT2 as a potential candidate gene for transport of $\mathrm{Fe}$ and may provide an alternative gene for iron biofortification of crops.

The nucleotide sequences of EfIRT2 gene from genomic DNA (gDNA) and predicted ORF using FGENESH (cDNA) were aligned using ClustalW tool and compared. UTR regions, start codon, stop codon and intron region are highlighted.

Multiple sequence alignment of amino acid sequences of EfIRT2 with IRT family members of selected plant species. Gaps (dashed lines) were introduced for optimal alignment. The region underlined with red bar indicates the conserved domain. Alignments were performed using ClustalW program.

Phylogenetic relationship between EfIRT2 and IRT members of other grass species (SiS. italicaL, Sb- S. bicolor, Zm- Z. mays L, Os$O$. sativa $\mathrm{L}, \mathrm{Bd}-B$. distachyon, $\mathrm{Hv}-H$. vulgare. Hypo* indicates hypothetical protein. The phylogenetic tree was constructed with the MEGA 6.0 software using Maximum Likelihood method, and the bootstrap values are in per cent, secondary structure of deduced EfIRT2 amino acid sequence predicted by PSIPRED protein structure prediction server.

\section{Acknowledgement}

The financial support provided by Department of Biotechnology, Ministry of Science and Technology, Government of India, New Delhi is thankfully acknowledged.

\section{References}

Boonyaves, K., W. Gruissem and Bhullar, N.K. 2016. NOD promoter-controlled AtIRT1 expression functions synergistically with NAS and FERRTIN genes to increase iron in rice grains. Plant Mol. Biol., 90: 207-215.

Chandel, G., R.K. Meena, M. Dubey and Kumar, M. 2014. Nutritional properties of minor millets: neglected cereals with potentials to combat malnutrition. Curr. Sci., 107(7): 1109-1111.

Doggett, H. 1989. Small millets- A selective overview. In: A. Seetharam, K. W. Riley, and G. Harinarayanan (Ed). Small millets in global agriculture, Oxford \& IBH, New Delhi, pp. 3-18.

Doyle, J.J. and Doyle, J.L. 1987. A rapid DNA isolation procedure for small quantities of fresh leaf tissue. Phytochem. Bull., 19: 11-15.

Eckhardt, U., A.M. Marques and Buckhoutet, T.J. 2001. Two iron-regulated cation transporters from tomato complement metal uptake-deficient yeast mutants. Plant Mol. Biol., 45: 437-448.

Eide, D., M. Broderius, J. Fett and Guerinot, M.L. 1996. A novel iron-regulated metal transporter from plants identified by functional expression in yeast. Proc. Natl. Acad. Sci. USA, 93: 5624-5628.

Goudia, B.D. and Hash, C.T. 2015. Breeding for high grain $\mathrm{Fe}$ and $\mathrm{Zn}$ levels in cereals. Int. J. Innov. Appl. Stud., 12(2): 342-354.

Grunes, D.L. and Allaway, W.H. 1985. 
Nutritional quality of plants in relation to fertilizer use. In: Fertilizer Technology and Use. Engelstad OP ed. Madison, WI: Soil Sci. Soc. America, pp. 589-619.

Guerinot, M.L. 2000. The ZIP family of metal transporters. Biochem. Biophys. Acta., 1465(12): 190-198.

Kerkeb, L., I. Mukherjee, I. Chatterjee, B. Lahner, D.E. Salt and Connolly, E.L. 2008. Iron induced turnover of the Arabidopsis IRON-REGULATED TRANSPORTER1 metal transporter requires lysine residues. Plant Physiol., 146: 1964-1973.

Lee, S. and An, G. 2009. Over-expression of OsIRT1 leads to increased iron and zinc accumulations in rice. Plant Cell Environ., 32(4): 408-416.

Liu, Y.G., N. Mitsukawa, T. Oosumi and Whittier, R.F. 1995. Efficient isolation and mapping of Arabidopsis thaliana $\mathrm{T}$ DNA insert junctions by thermal asymmetric interlaced PCR. Plant J., 8(3): 457-463.

Lucca, P., R. Hurrell and Potrykus, I. 2001. Genetic engineering approaches to improve the bioavailability and the level of iron in rice grains. Theor. Appl. Genet., 102(2-3): 392-397.

Masuda, H., M. Suzuki, K.C. Morikawa, T. Kobayashi, H. Nakanishi, M. Takahashi, M. Saigusa, S. Mori and Nishizawa, N.K. 2008. Increase in iron and zinc concentrations in rice grains via the introduction of barley genes involved in phytosiderophore synthesis. Rice, 1(1): 100-108.

Muneer, S., B.R. Jeong, T.H. Kim, J.H. Lee and Soundararajan, P. 2014. Transcriptional and physiological changes in relation to Fe uptake under conditions of Fe-deficiency and $\mathrm{Cd}$ toxicity in the roots of Vigna radiata $\mathrm{L}$. J. Plant Res., 127: 731-742.

Patel, G.S., M. Dubey and Chandel, G. 2015.
Characterization of metal homeostasis related rice gene orthologs in nutri-rich minor millets. Intl. J. Plant Animal Environ. Sci., 5(4): 14-23.

Patron, N.J. and Waller, R.F. 2007. Transit peptide diversity and divergence: A global analysis of plastid targeting signals. BioEssays, 29(10): 1048-1058.

Shanmugam, V., J.C. Lo, C.L. Wu, S.L. Wang, C.C. Lai, E.L. Connolly, J.L. Huang and Yeh, K.C. 2011. Differential expression and regulation of ironregulated metal transporters in Arabidopsis halleri and Arabidopsis thaliana - the role in zinc tolerance. New Phytol., 190(1): 125-137.

Stoltzfus, R.J. and Dreyfuss, M.L. 1998. Micronutrient deficiency disorders: Guidelines for the use of iron supplements to prevent and treat iron deficiency anemia: ILSI Press Washington DC. pp. 1-39.

Tan, S., R. Han, P. Li, G. Yang, S. Li, P. Zhang, W.B. Wang, W.Z. Zhao and Yin, L.P. 2015. Over expression of the MxIRT1 gene increases iron and zinc content in rice seeds. Trans. Res., 24(1): 109-122.

Terry, N. and Abadía, J. 1986. Function of iron in chloroplasts. J. Plant Nutri., 9(37): 609-646.

Trijatmiko, K.R., C. Dueñas, N. Tsakirpaloglou, L. Torrizo, F.M. Arines, C. Adeva, et al. 2016. Biofortified indica rice attains iron and zinc nutrition dietary targets in the field. Sci. Rep., 6: 19792.

Vasconcelos, M., K. Datta, N. Oliva, M. Khalekuzzaman, L. Torrizo, S. Krishnan, M. Oliveira, F. Goto and Datta, S.K. 2003. Enhanced iron and zinc accumulation in transgenic rice with the ferritin gene. Plant Sci. 164(3): 371-378.

Vatansever, R., E. Filiz and Ozyigit, I.I. 2015. Genome-wide analysis of iron-regulated 
transporter 1 (IRT1) genes in plants. Hortic. Environ. Biotechnol., 56(4): 516-523.

Vert, G., M. Barberon, E. Zelazny, M. Séguéla, J.F. Briat and Curie, C. 2009. Arabidopsis IRT2 cooperates with the high-affinity iron uptake system to maintain iron homeostasis in root epidermal cells. Planta, 229(6): 11711179.

Vert, G.J.F. Briat and Curie, C. 2001. Arabidopsis IRT2 gene encodes a root- periphery iron transporter. Plant $J$., 26(2): 181-189.

Vert, G., N. Grotz, F. Dédaldéchamp, F. Gaymard, M.L. Guerinot, J.F. Briat and Curie, C. 2002. IRT1, an Arabidopsis transporter essential for iron uptake from the soil and for plant growth. Plant Cell, 14(6): 1223-1233.

WHO. 2002. Reducing risk and promoting healthy life: Report of a World Health Organization Scientific Group, Geneva, Switzerland.

\section{How to cite this article:}

Manape, T.K., S. Varanavasiappan, M. Raveendran, S. Robin, S. Rajeswari and Sudhakar, D. 2017. Isolation and In Silico Analysis of Iron Regulated Transporter 2 Gene from Indian Barnyard Millet (Echinochloa frumentacea L.) Int.J.Curr.Microbiol.App.Sci. 6(4): 1576-1587. doi: https://doi.org/10.20546/ijcmas.2017.604.194 